\title{
Gas signatures from Escherichia coli and Escherichia coli-inoculated human whole blood
}

\author{
Brandon J Umber ${ }^{1 \dagger}$, Hye-Won Shin ${ }^{2,3^{*}+}$, Simone Meinardi ${ }^{1}$, Szu-Yun Leu ${ }^{2,3}$, Frank Zaldivar ${ }^{2,3}$, Dan M Cooper ${ }^{2,3}$ \\ and Donald R Blake ${ }^{1}$
}

\begin{abstract}
Background: The gaseous headspace above naïve Escherichia Coli (E. coli) cultures and whole human blood inoculated with E. coli were collected and analyzed for the presence of trace gases that may have the potential to be used as novel, non-invasive markers of infectious disease.

Methods: The naive E. coli culture, LB broth, and human whole blood or E. coli inoculated whole blood were incubated in hermetically sealable glass bioreactors at $37^{\circ} \mathrm{C}$ for $24 \mathrm{hrs}$. LB broth and whole human blood were used as controls for background volatile organic compounds (VOCs). The headspace gases were collected after incubation and analyzed using a gas chromatographic system with multiple column/detector combinations.

Results: Six VOCs were observed to be produced by E. coli-infected whole blood while there existed nearly zero to relatively negligible amounts of these gases in the whole blood alone, LB broth, or E. coli-inoculated LB broth. These VOCs included dimethyl sulfide (DMS), carbon disulfide $\left(\mathrm{CS}_{2}\right)$, ethanol, acetaldehyde, methyl butanoate, and an unidentified gas S. In contrast, there were several VOCs significantly elevated in the headspace above the E. coli in LB broth, but not present in the E. coli/blood mixture. These VOCs included dimethyl disulfide (DMDS), dimethyl trisulfide (DMTS), methyl propanoate, 1-propanol, methylcyclohexane, and unidentified gases R2 and Q.

Conclusions: This study demonstrates 1) that cultivated E. coli in LB broth produce distinct gas profiles, 2) for the first time, the ability to modify E. coli-specific gas profiles by the addition of whole human blood, and 3) that E. colihuman whole blood interactions present different gas emission profiles that have the potential to be used as noninvasive volatile biomarkers of $E$. coli infection.
\end{abstract}

Keywords: Gas biomarker; Volatile organic compounds (VOCs); Escherichia coli; Cell culture; Human whole blood culture; Dimethyl sulfide (DMS); Carbon disulfide $\left(\mathrm{CS}_{2}\right)$; Ethanol; Acetaldehyde; Methyl butanoate

\section{Background}

Over the past decade, the interest in using exhaled gases as non-invasive biomarkers in clinical diagnostics and therapeutic monitoring has steadily increased [1]. Considerable efforts have been made to determine clinically applicable breath biomarkers for such conditions as asthma, diabetes, and various cancers [2-7]. Evidence also exists that cultivated microorganisms can generate species or genus-specific profiles of VOCs [8-13]. Additionally, unique gas signatures have been observed in the exhaled

\footnotetext{
*Correspondence: hyewons@uci.edu

${ }^{\dagger}$ Equal contributors

2Department of Pediatrics, University of California, Irvine, CA 92697, USA

${ }^{3}$ Institute for Clinical and Translational Sciences, University of California, Irvine, CA 92697, USA

Full list of author information is available at the end of the article
}

breath of patients with specific infections, including bronchopneumonia [14] and Helicobacter pylori [15].

Identifying and quantifying gases in the exhaled human breath provide a non-invasive means of obtaining information about host responses to infection. However, with the exception of nitric oxide, the cellular sources or mechanisms responsible for the observed gases have not been fully investigated. It is conceivable that the host immune response may yield gases unique to one pathogen or another. Escherichia Coli (E. coli) was used as a model infectious organism to 1 ) determine the unique gas profile of bacteria in a "naïve" state and 2) investigate the VOCs that result from the bacteria and whole blood interactions. VOC profiles found in the interaction of bacteria and immune cells containing whole blood may

\section{实}


then provide a beginning interpretation of the exhaled breath gases from infected subjects.

A hermetically sealable bioreactor was used to grow the cultures and collect the gaseous headspace. The headspace was then analyzed for trace gases produced and released by the microorganisms growing in culture using a multi-column and multi-detector analytical gas chromatography (GC) methodology [16].

This approach will soon be extended to additional infectious agents and it is anticipated that the technology will eventually demonstrate the capability to discriminate between multiple infectious pathogens by means of their unique VOC profiles.

\section{Methods}

Blood Sampling. The blood was drawn using EDTAtreated vacutainers from adult male subjects through the Institute for Clinical Translational Sciences (ICTS) general blood donor program. Subjects having a history of any chronic medical conditions or use of any medications were excluded from the study. The Institutional Review Board at the University of California, Irvine, approved the study.

\section{E. Coli culture and headspace Gas collection}

E. coli was purchased from Invitrogen (One Shot TOP10 Chemically Competent, Invitrogen, NY). The genotype of this E. coli is similar to DH10B strain. The complete genome sequence has been reported elsewhere (http:// www.ncbi.nlm.nih.gov/pubmed/18245285). Gibco LB broth from Invitrogen was used for the study. The vials of E. coliinoculated whole blood $\left(1 \times 10^{6}\right.$ E. coli $/ 10 \mathrm{~mL}$ whole blood $)$ and naïve E. coli inoculated LB broth $\left(1 \times 10^{6} \mathrm{E}\right.$. Coli/ $10 \mathrm{~mL} \mathrm{LB}$ ) were placed inside bioreactors specifically designed to collect the gaseous headspace above aqueous cultures [16]. For comparison, vials of LB broth only $(10 \mathrm{~mL})$ or vials of whole blood only $(10 \mathrm{~mL})$ were also placed inside bioreactors. To minimize ambient gaseous contaminants, each bioreactor was flushed with whole air containing low levels of VOCs and $5 \% \mathrm{CO}_{2}$ for $10 \mathrm{mi}-$ nutes at $125 \mathrm{~mL}$ per minute. The bioreactors were then placed in an incubator at $37^{\circ} \mathrm{C}$ for $24 \mathrm{hrs}$. The headspace gases were collected after incubation and analyzed using a gas chromatographic system with multiple column/ detector combinations [16-18]. Following sample collection, the bioreactor was disassembled and the cells were immediately collected and counted.

\section{GC system}

The analyses of the headspace gases were performed on a system previously developed to measure trace atmospheric gases [17]. Briefly, a $233 \mathrm{~cm}^{3}$ (at STP) sample was cryogenically pre-concentrated and injected into a multicolumn/detector GC system. The system consists of three Hewlett-Packard 6890 GC units (Wilmington, DE) using a combination of columns and detectors capable of separating and quantifying hundreds of gases, including, but not limited to, non-methane hydrocarbons (NMHCs), alkyl nitrates, and halocarbons in the ppbv to pptv range $\left(10^{-9}-10^{-12}\right)$. The detectors include flame ionization detectors (FIDs), electron capture detectors (ECDs), and a mass selective detector (MSD). Preliminary identifications of the unknown compounds were made using GC-MSD and verification was obtained by injecting the diluted headspace of pure compounds (Sigma-Aldrich, St. Louis, MO) to ensure that both the elution time and the mass spectrum matched that of the unknown.

\section{Data analysis}

Four study conditions, Broth only, Broth + E. coli, Blood only, and Blood $+E$. coli were evaluated in each of the 10 experimental days. The same blood sample and $E$. coli sample were used in the same day. A total of 117 gases were examined for each sample. Thirty-eight gases were excluded; of these, 31 gases were below the limit of detection in over $80 \%$ of the samples and seven gases had concentrations less than 100 pptv in all samples. For any gas that could not be detected in a sample, the level was set to zero Wilcoxon signed-rank test, a nonparametric method for paired data, was used to compare the difference between Broth only and Broth $+E$. coli, between Blood only and Blood $+E$. coli, between Broth $+E$. coli and Blood + E. coli, and between Broth only and Blood only. The method was chosen because the sample size was small, the distributions of most gases were highly skewed, and the experiments performed on the same day were considered more correlated than those performed on different days. Multiple-comparison adjustment was further applied using Benjamini and Hochberg's false discover rate (FDR) method [19]. A comparison was considered significant if $\mathrm{FDR}<0.01$. All analyses were performed using SAS 9 (Cary, NC) and all data were presented with median and range (minimum, maximum).

\section{Results}

After statistical analysis, 40 gases were allocated into five categories based on the pattern of gas release: category 1 : VOCs elevated from E. coli-inoculated human whole blood, (see Table 1 and Figure 1); category 2: VOCs elevated from $E$. coli in LB broth (see Table 1 and Figure 2); category 3: VOCs elevated from naïve $E$. coli in broth, but decreased by E. coli-inoculated whole blood (see Table 1, and Figure 3); category 4: VOCs mainly from pure LB broth only (see Table 2 and Figure 4); category 5: VOCs mainly from human whole blood only (see Table 3 and Figure 5).

In category 1 , there were six VOCs observed to be significantly increased from $E$. coli-inoculated whole blood 
Table 1 VoCs of interest

\begin{tabular}{|c|c|c|c|c|c|}
\hline \multirow[t]{2}{*}{ Gas } & \multirow{2}{*}{$\begin{array}{l}\text { Stat. } \\
\text { diff. }\end{array}$} & \multicolumn{2}{|c|}{ Broth } & \multicolumn{2}{|c|}{ Blood } \\
\hline & & & + E. coli & & + E. coli \\
\hline \multicolumn{6}{|c|}{ Category 1: VOCs elevated in E. coli-infected blood } \\
\hline Diemthyl sulfide [pptv] & 2,4 & $970(310,2310)$ & $16010(180,29500)$ & $3770(1250,8820)$ & $95920(25740,234400)$ \\
\hline Carbon disulfide [pptv] & $2,3,4$ & $85(55,470)$ & $295(80,790)$ & $4390(2450,10040)$ & $8940(2620,16550)$ \\
\hline Acetaldehyde [ppbv] & & $736(558,1089)$ & $645(44,1359)$ & $45(22,145)$ & $1158(208,3493)$ \\
\hline Ethanol [ppbv] & $1,2,3$ & $202(28,564)$ & $8388(2037,10867)$ & $218(5,604)$ & $15486(7199,40441)$ \\
\hline Unk $S^{\S}$ & 2,3 & $31(0,316)$ & $74(12,267)$ & $675(0,3311)$ & $15001(2208,37426)$ \\
\hline Methyl Butanoate [pptv] & & $0(0,25)$ & $0(0,40)$ & $60(0,405)$ & $2675(330,9720)$ \\
\hline \multicolumn{6}{|c|}{ Category 2: VOCs elevated in naïve E. coli in LB broth } \\
\hline Isoprene [pptv] & 1,4 & $0(0,50)$ & $1590(665,2175)$ & $1040(350,2785)$ & $1200(455,2050)$ \\
\hline Carbonyl sulfide (OCS) [pptv] & 1 & $2240(1440,4850)$ & $8360(4360,20180)$ & $3850(1970,22040)$ & $6540(3810,30340)$ \\
\hline Unk $R 1^{\S}$ & & $7474(1568,42622)$ & $116738(15070,1005677)$ & $3758(105,20243)$ & $2435(785,10277)$ \\
\hline \multicolumn{6}{|c|}{ Category 3: VOCs elevated in naïve E. coli but substantially lower from co-culture of $E$. coli and whole blood } \\
\hline Dimethyl disulfide [ppbv] & $1,3,4$ & $164(133,185)$ & $354(182,537)$ & $0.7(0.3,2)$ & $2(0.6,4)$ \\
\hline Methyl Propanoate [pptv] & & $3300(2100,4300)$ & $14500(5660,21000)$ & $400(0,1400)$ & $600(0,1100)$ \\
\hline Dimethyl trisulfide [pptv] & 1,3 & $2900(1900,9700)$ & $160400(22700,253300)$ & $800(10,6900)$ & $400(150,5400)$ \\
\hline Unk_Q $Q^{\S}$ & & $2052(0,13997)$ & $57320(6317,467654)$ & $620(0,6232)$ & $289(0,3787)$ \\
\hline 1-Propanol [pptv] & & $175(0,90200)$ & $757300(472900,1920800)$ & $700(0,93600)$ & $33400(4100,90200)$ \\
\hline Methylcylohexane [pptv] & & $220(60,990)$ & $1600(850,3200)$ & $130(0,1720)$ & $170(80,980)$ \\
\hline Unk R2 ${ }^{\S}$ & & $416(0,5269)$ & $15852(2228,152789)$ & $767(0,9829)$ & $674(0,8522)$ \\
\hline
\end{tabular}

1: significantly different between Broth only and Broth + E. coli; 2 : significantly different between Blood only and Blood $+E$. coli; 3 : significantly different between Broth + E. coli i and Blood + E. coli; 4 : significantly different between Broth only and blood only.

Data were presented with median and range (minimum, maximum).

sunknown peaks were presented as area under the curve.

when compared to VOCs from whole blood alone. These VOCs include dimethyl sulfide, carbon disulfide, ethanol, acetaldehyde, methyl butanoate and an unidentified gas $S$ (see Table 1 and Figure 1 for examples of this category). Ethanol was also emitted from the E. coli cultured in the LB broth; however, the concentrations were relatively small when compared to the $E$. coli-inoculated whole blood (see Figure 1B).

In contrast, ten VOCs (see Table 1, category 2 and 3) were significantly elevated from E. coli in LB broth (Figures 2 and 3 show several examples). Isoprene, carbonyl sulfide (OCS), and unidentified gas peak R1 were significantly elevated in the headspace of $E$. coli in LB broth. These gases detected in the headspace of whole blood, and E. coli-inoculated whole blood. However, emitted isoprene, carbonyl sulfide and unidentified gas peak R1 levels from whole blood and E. coli-inoculated whole blood were not different (see Figure 2). Interestingly, seven out of these ten VOCs were substantially lower in the presence of human whole blood (see category 3 and Figure 3). These VOCs included dimethyl disulfide, dimethyl trisulfide, methylpropanoate, 1-propanol, methylcyclohexane, and unidentified gas peaks R2, and Q. The emitted levels from whole blood and E. coli-inoculated whole blood were not different in these seven gases.

Table 2 lists 16 VOCs that were observed to be significantly higher in LB broth when compared to the levels in whole blood (category 4). The emitted levels of 14 out of total 16 gases in this category (except n-Propylbenzene and unidentified gas peak $\mathrm{M}$ ) were decreased in the presence of $E$. coli. Human whole blood emitted trace amount of these gases, and the levels of these gases were not altered in the presence of E. coli. Butanone levels in four different conditions (in the LB broth, in the E. coli in the LB broth, human whole blood, and E. coli-inoculated whole blood) are presented in Figure 4 as an example.

Table 3 lists eight VOCs that mainly originated from human whole blood (category 5). The emitted levels of these eight VOCs were substantially higher in the whole blood only when compared to the levels in LB broth. Interestingly, co-incubation of $E$. coli in human blood did not alter the concentrations of the gases.

Many elevated whole blood compounds were also detected in the headspace of the blood-collecting vacutainer and were rejected as carried-over contaminants. These include: styrene, 3-methylpentane, n-hexane, cyclohexane, methylcyclopentane, and 2-methyl-2-butene. 


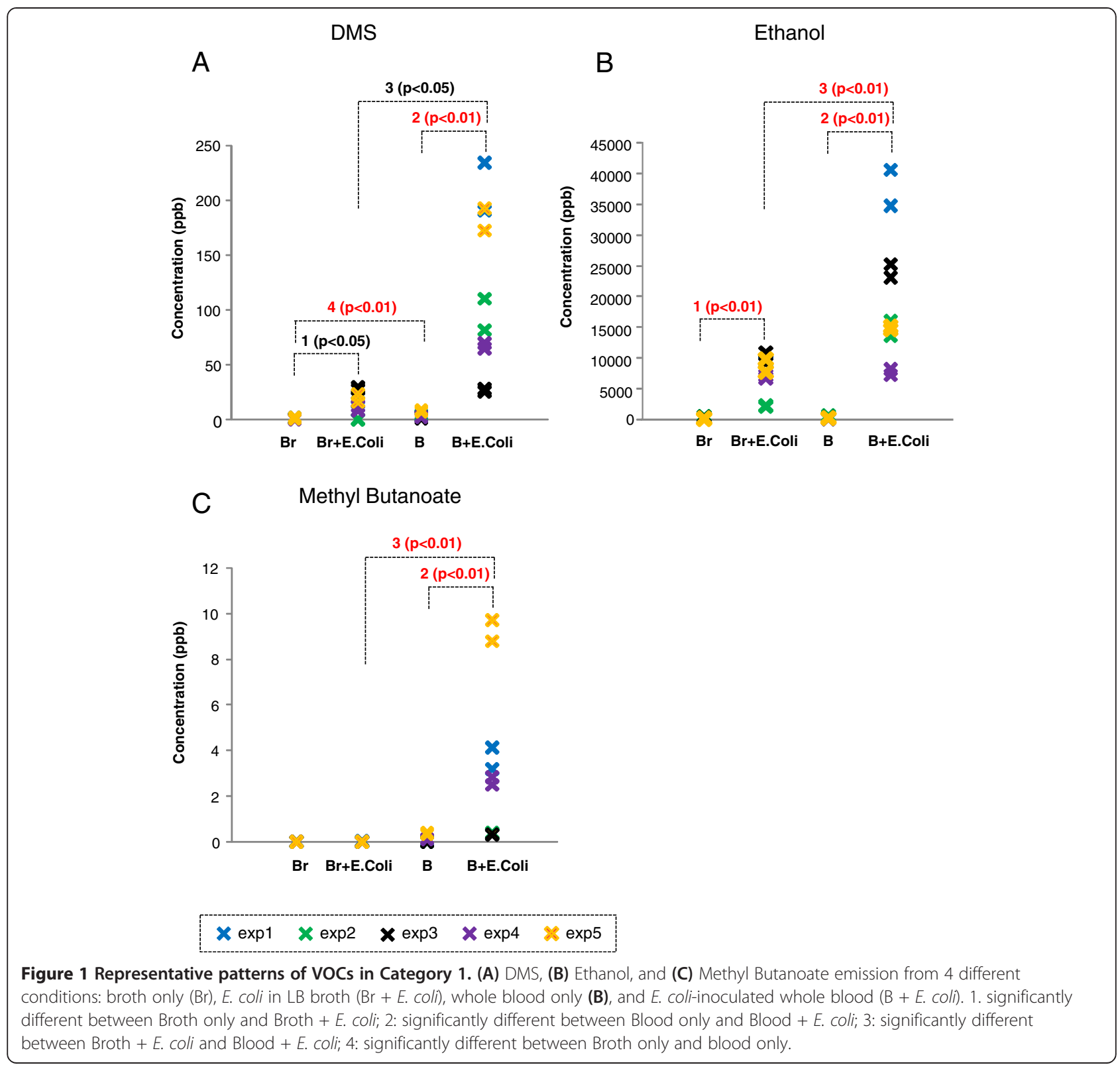

\section{Discussion}

Specific VOCs released by E. coli in either LB broth or human blood were collected and compared to the levels emitted from LB broth or blood alone. Headspace gas samples were collected after incubation for $24 \mathrm{hr}$ at $37^{\circ} \mathrm{C}$ from $10 \mathrm{~mL}$ samples inoculated with (or without) $10^{6} \mathrm{E}$. coli. This study demonstrates 1 ) that cultivated E. coli in LB broth produces distinct gas profiles, 2) for the first time the ability to modify $E$. coli-specific gas profiles by the addition of whole human blood (i.e., Methyl Propanoate was highly emitted from $E$. coli in LB broth, but barely detected in human whole blood), and 3) of most significance, that the data suggests that $E$. coli-human whole blood interaction has different gas emission profiles that can be used as non-invasive markers of E. coli infection (i.e., methyl butanoate).

The co-culture of $E$. coli in human whole blood emitted appreciable amounts of dimethyl sulfide when compared to the level from naive $E$. coli in the LB broth (Figure 1A). Dimethyl sulfide is a sulfur-containing odorous gas known to be released from marine phytoplankton and algae, and its release has been reported to protect algae and phytoplankton against environmental changes in salinity, radiation, and temperature [20,21]. Dimethyl sulfide released from damaged phytoplankton has also been proposed to act as a deterrent, or chemical weapon, against consumption by zooplankton [22]. In addition, it has been proposed that some microorganisms are able 


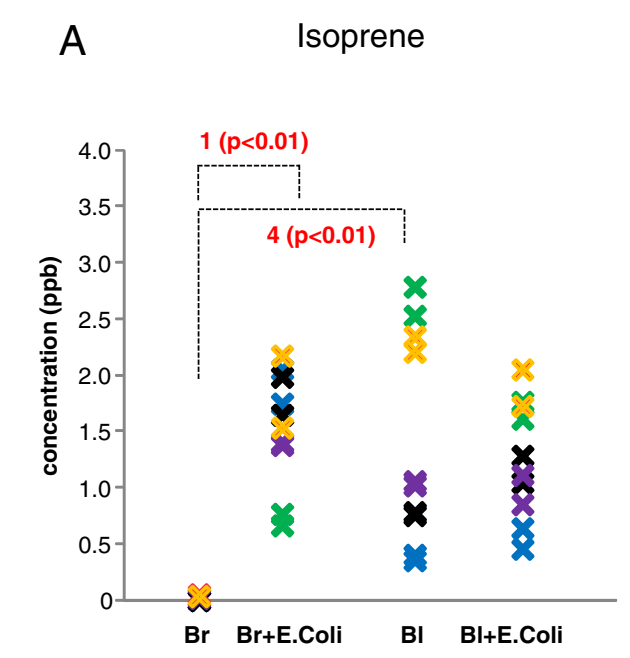

\section{B Carbonyl sulfide (OCS)}

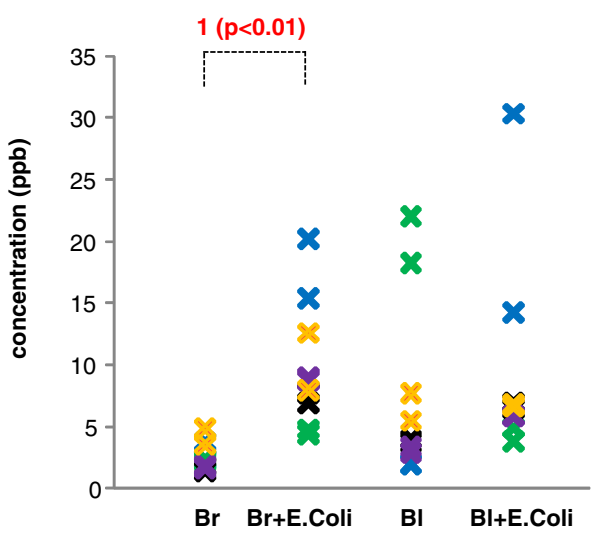

\section{$\times \exp 1 \quad \times \exp 2 \quad \times \exp 3 \quad \times \exp 4 \quad x \exp 5$}

Figure 2 Representative patterns of VOCs in Category 2. (A) Isoprene and (B) carbonyl sulfide (OCS) emission from 4 different conditions: only $(\mathrm{Br})$, E. coli in $\mathrm{LB}$ broth $(\mathrm{Br}+E$. coli), whole blood only (B), and E. coli-inoculated whole blood $(\mathrm{B}+\mathrm{E}$. coli). 1: significantly different between Broth only and Broth + E. coli i; 2 : significantly different between Blood only and Blood + E. coli i; 3 : significantly different between Broth + E. coli and Blood + E. coli; 4: significantly different between Broth only and blood only.

to generate gaseous dimethyl sulfide from dimethylsulphoniopropionate [23-25]. A significant concentration of dimethyl sulfide was observed in the headspace of $E$. coli-inoculated whole blood, whereas the headspace of E. coli in LB broth contained much less dimethyl sulfide (Figure 1A). This is the first observation that E. coli- inoculated human whole blood produces dimethyl sulfide. Allardyce and colleagues reported that dimethyl sulfide was detected from E. coli culture using BacT/ ALERT, which contains a mixture of media with blood $[8,26]$. It is interesting to speculate the possible roles for dimethyl sulfide. Considering that dimethyl sulfide is a
A Dimethyl disulfide (DMDS)

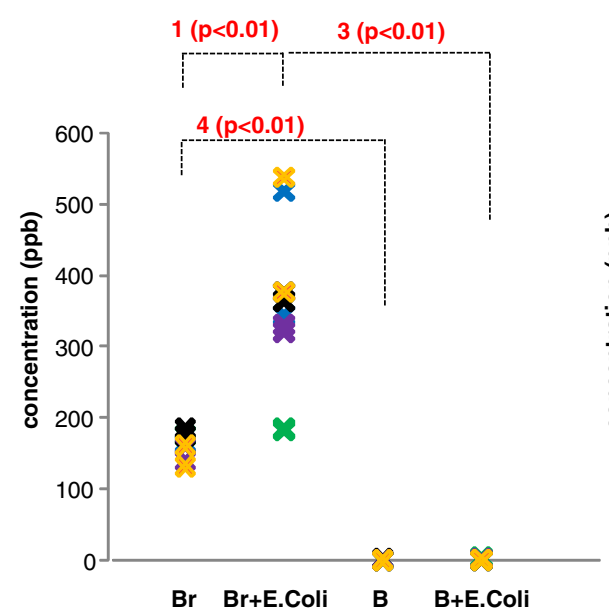

B

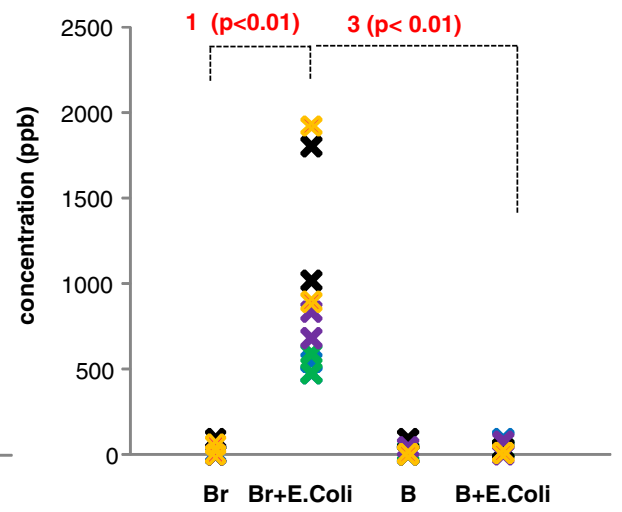

$$
\boldsymbol{x} \exp 1 \times \exp 2 x \exp 3 \times \exp 4 \quad x \exp 5
$$

Figure 3 Representative patterns of VOCs in Category 3. (A) Dimethyl disulfide (DMDS) and (B) 1-propanol emission from 4 different conditions such as broth only $(\mathrm{Br}), \mathrm{E}$. coli in $\mathrm{LB}$ broth $(\mathrm{Br}+\mathrm{E}$. coli), whole blood only (B), and E. coli-inoculated whole blood (B + E. coli). 1: significantly different between Broth only and Broth + E. coli; 2 : significantly different between Blood only and Blood + E. coli; 3 : significantly different between Broth + E. coli and Blood + E. coli; 4: significantly different between Broth only and blood only. 
Table 2 Gases mainly from pure broth

\begin{tabular}{|c|c|c|c|c|}
\hline \multirow[t]{3}{*}{ Gas } & \multicolumn{4}{|c|}{ Category 4 Gases mainly from LB broth (significantly higher in broth only compared to whole blood only) } \\
\hline & \multicolumn{2}{|c|}{ Broth } & \multicolumn{2}{|c|}{ Blood } \\
\hline & & + E. coli & & + E. coli \\
\hline Ethyl nitrate [pptv] & $429(371,448)$ & $233(32,284)$ & $28(17,38)$ & $28(21,35)$ \\
\hline Methyl nitrate [pptv] & $705(670,825)$ & $446(38,534)$ & $29(27,35)$ & $29(26,36)$ \\
\hline 2-Propyl nitrate [pptv] & $162(147,177)$ & $103(30,125)$ & $20(14,29)$ & $20(18,33)$ \\
\hline 2-Methylpropanal [pptv] & $90900(56900,203300)$ & $4300(700,8900)$ & $2010(100,600)$ & $600(200,1300)$ \\
\hline 3-Methylhexane [pptv] & $2000(1120,3290)$ & $1020(660,1660)$ & $510(400,1850)$ & $530(220,1410)$ \\
\hline 2,2,4-Trimethylpentane [pptv] & $9140(8030,9940)$ & $6100(1660,7140)$ & $700(360,1220)$ & $810(620,1160)$ \\
\hline$n$-Decane [pptv] & $100(70,140)$ & $50(30,50)$ & $60(30,70)$ & $60(30,80)$ \\
\hline Benzene [pptv] & $93640(50700,114580)$ & $25910(300,72270)$ & $1100(0,2070)$ & $1030(440,1550)$ \\
\hline Toluene [pptv] & $98930(54460,129080)$ & $30870(1850,69270)$ & $1210(670,2420)$ & $1680(720,1880)$ \\
\hline Ethylbenzene [pptv] & $640(250,950)$ & $220(40,530)$ & $150(80,280)$ & $170(120,290)$ \\
\hline Styrene [pptv] & $1130(670,1950)$ & $800(290,1180)$ & $280(140,1110)$ & $360(200,820)$ \\
\hline n-Propylbenzene [pptv] & $40(20,70)$ & $40(20,110)$ & $20(5,40)$ & $30(15,70)$ \\
\hline Butanal [pptv] & $169900(60100,238800)$ & $0(0,8900)$ & $700(200,17100)$ & $600(0,34500)$ \\
\hline Hexanaldehyde [pptv] & $1250(700,3800)$ & $485(275,1600)$ & $450(250,3050)$ & $575(175,2150)$ \\
\hline Butanone [pptv] & $478800(374600,707000)$ & $339600(219900,555700)$ & $5600(2300,15900)$ & $9500(6400,31200)$ \\
\hline Unk $M^{\S}$ & $10530(5841,20041)$ & $12854(7971,44834)$ & $1095(263,2664)$ & $1633(359,3345)$ \\
\hline
\end{tabular}

Data were presented with median and range (minimum, maximum).

§unknown peaks were presented as area under the curve.

cryoprotectant for algae, dimethyl sulfide could be a mediator of survival of blood cells in response to the stresses of bacterial infection or the response of $E$. coli in the face of the bactericidal components of whole blood. Other studies utilizing different media/broth to

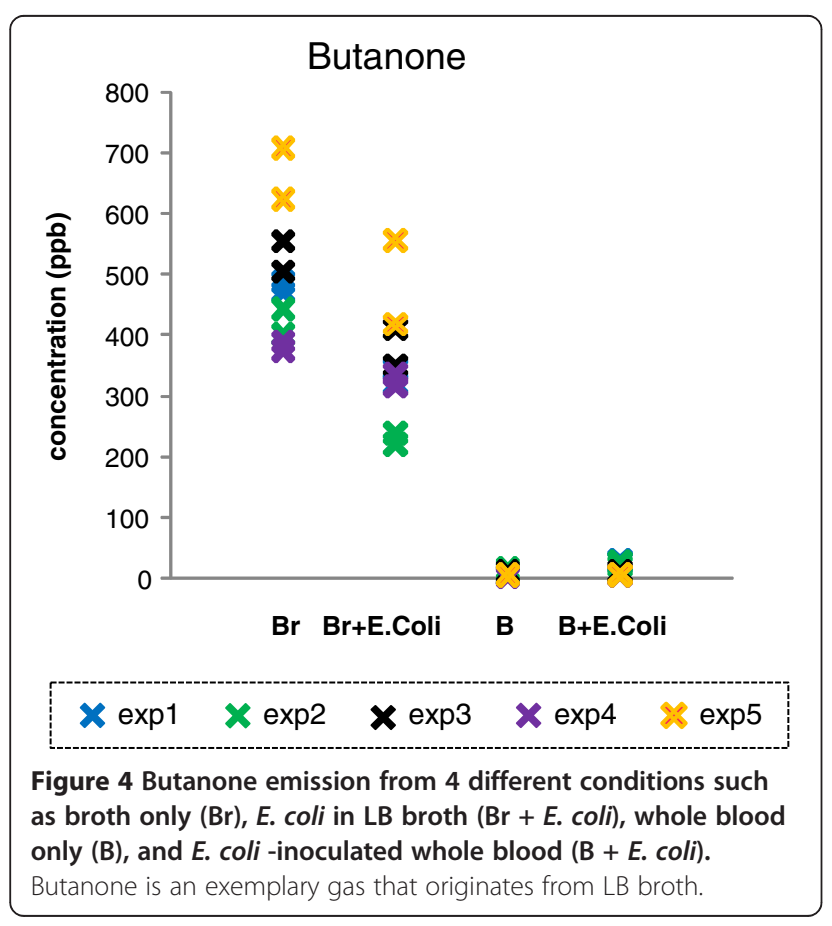

culture E. coli did not observe dimethyl sulfide in the headspace above the culture $[9,13]$.

Various strains of $E$. coli have been reported to metabolize glucose (and other sugars) to generate ethanol regardless of culture medium or broth used [3,27-34]. In the current study, ethanol has been detected in E. coli in LB broth and in the presence of human whole blood (Figure 1B). E. coli in LB broth emitted greater than 8 ppmv ethanol. The emission level was even greater $(>15$ ppmv) when $E$. coli was mixed with human blood. It is likely that the ethanol emission from $E$. coli depends on the available glucose in the LB broth or human whole blood.

Acetaldehyde has previously been detected in exhaled human breath $[35,36]$ and in human lung cancer cell line cultures [37-39]. We previously demonstrated that both malignant myelocytic white blood cells such as HL60 and neutrophils are capable of producing acetaldehyde $(16 ; 18)$. The current study also demonstrates that $E$. coli-inoculated whole blood obtained from healthy subjects emitted appreciable amounts of acetaldehyde into the gas phase greater than the emission from whole blood (Table 1). In addition, acetaldehyde has been detected from other strains of $E$. coli and other microorganisms such as Pseudomonas cultured in human blood and medium mixture $[8,26]$. The LB broth itself also emits some acetaldehyde. However, the levels were not altered in the presence of E. coli in LB broth. This observation 
Table 3 Gases mainly from whole human blood

\begin{tabular}{|c|c|c|c|c|}
\hline \multirow[t]{3}{*}{ Gas } & \multicolumn{4}{|c|}{$\begin{array}{l}\text { Category } 5 \text { Gases mainly from whole human blood (significantly higher in whole blood only compared } \\
\text { to broth only) }\end{array}$} \\
\hline & \multicolumn{2}{|c|}{ Broth } & \multicolumn{2}{|c|}{ Blood } \\
\hline & & + E. coli & & + E. coli \\
\hline n-Pentane [pptv] & $50(0,160)$ & $10(0,165)$ & $1220(835,1900)$ & $1625(815,2440)$ \\
\hline Methanol [ppbv] & $48(34,132)$ & $62(41,110)$ & $300(210,346)$ & $378(226,704)$ \\
\hline n-Heptane [pptv] & $0(0,315)$ & $150(30,165)$ & $370(260,915)$ & $700(210,4305)$ \\
\hline 2,3,4-Trimethylpentane [pptv] & $35(0,130)$ & $55(0,205)$ & $125(105,275)$ & $145(130,365)$ \\
\hline alpha-Pinene [pptv] & $5(0,15)$ & $5(0,60)$ & $40(20,220)$ & $60(15,370)$ \\
\hline Methyl chloride $\left(\mathrm{CH}_{3} \mathrm{Cl}\right)$ [pptv] & $1045(800,1390)$ & $1140(675,1815)$ & $2190(1215,2670)$ & $1890(1235,3025)$ \\
\hline Dibromomethane $\left(\mathrm{CH}_{2} \mathrm{Br}_{2}\right)$ [pptv] & $1(0,2)$ & $1(0,2)$ & $47(11,75)$ & $54(10,106)$ \\
\hline i-Pentane [pptv] & $225(0,870)$ & $210(0,510)$ & $1400(545,2395)$ & $1310(0,4770)$ \\
\hline
\end{tabular}

Data were presented with median and range (minimum, maximum).

and others may suggest that acetaldehyde is likely a metabolic byproduct of the interaction between $E$. coli and the various components of whole blood $[40,41]$.

Other VOCs generated only in the E. coli-inoculated whole blood were methyl butanoate and a gas that remains unidentified, unknown S. Methyl butanoate has been detected in the exhaled breath of patients with liver disorders [42]. These gases have the potential to be breath biomarkers of $E$. coli infection since these VOCs only appear in the E. coli-inoculated whole blood.

There were four VOCs found in the headspace above cultured $E$. coli in LB broth that were significantly lower

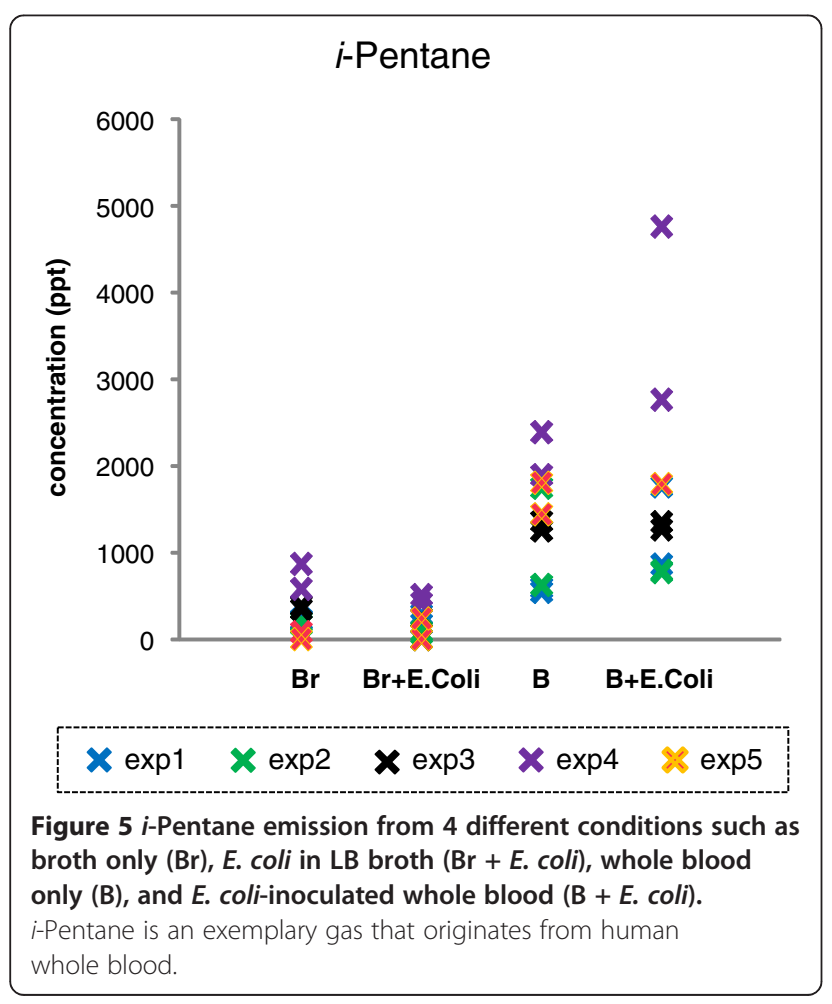

in the presence of human whole blood. These VOCs include 1-propanol and the unknown VOCs R1, R2, and Q (see Table 1). Note that both LB broth and human whole blood generate negligible amounts of these VOCs. It remains unclear whether these VOCs are produced by $E$. coli and metabolized by certain components in the blood or the gas production itself was suppressed in the blood. One such possible mechanism for 1-propanal would be the production of 1-propanol by E. coli [43] and then, when co-cultured with whole blood, 1-propanol is metabolized by alcohol dehydrogenase in the human whole blood [44]. These compounds may prove interesting in cellular mechanistic studies as they have potentially been catabolised by E. coli and/or whole blood.

Isoprene, carbonyl sulfide, and unidentified gas peak R1 were higher in the headspace of $E$. coli in LB broth when compared to the LB broth only. carbonyl sulfide has been detected in the human breath [14]. Breath carbonyl sulfide concentrations were significantly higher in subjects with cystic fibrosis and it has been suggested that it originates from respiratory bacterial colonization. In effect, subjects with poorer pulmonary function tended to have greater breath carbonyl sulfide concentrations [14]. Isoprene has also been detected in exhaled human breath, and its possible association with blood cholesterol levels [45,46] and end-stage renal failure [47] has been suggested. In addition, various bacterial species, including $E$. coli, have been reported to produce isoprene, though emitted isoprene levels varied depending on the culture medium [48]. In the current study, $E$. coli contributes to isoprene emission with median value of $1600 \mathrm{pptv}$ when cultured in the LB broth. Human whole blood obtained from healthy subjects emitted a median value of $1000 \mathrm{pptv}$ of isoprene. Interestingly, $E$. coli inoculation into the whole blood does not affect emitted isoprene levels. This observation may suggest that isoprene release may be governed by different 
mechanisms when E. coli is cultured in the LB broth and human whole blood.

In contrast, there are certain VOCs that originated from LB broth only or human whole blood only that are not increased by the addition of $E$. coli (Table 2, category 4 and Figure 4; Table 3, category 5 and Figure 5). For example, butanone (an exemplary gas, category 4) and $i$ Pentane (an exemplary gas, category 5) emissions were observed either in LB broth only or human whole blood only, respectively. However, the emission levels were not altered in the presence of $E$. coli; the VOCs under these categories were not considered of interest in searching for $E$. coli -associated gas biomarkers.

\section{Conclusions}

The current study demonstrates that cultivated E. coli produces distinct gas profiles depending on the medium used (i.e., LB broth or human whole blood). In addition, and of most significance, the data suggests that the interaction between E. coli and human whole blood presents a different gas emission profile that may have the potential to be used as non-invasive marker of $E$. coli infection. Additional investigations will be required to provide a more specific understanding of how the immune response of whole blood specifically alters the gas signature of invading $E$. coli. These data also provide the beginning of an inventory of VOCs associated with $E$. coli -the necessary first step from which an exploration of other pathogenic microorganisms can follow.

\section{Abbreviations}

VOCs: Volatile organic compounds; E. coli: Escherichia Coli; DMS: Dimethyl sulfide; $\mathrm{CS}_{2}$ : Carbon disulfide; OCS: Carbonyl sulfide; DMDS: Dimethyl disulfide; DMTS: Dimethyl trisulfide.

\section{Competing interests}

The authors declare that they have no competing interests.

\section{Authors' contributions}

HWS and BJU designed and performed experiments and wrote the manuscript. SM participated in chemical analysis of volatile gases obtained from E.coli cultures. FPZ contributed experimental design and participated in culturing E.coli. SYL carried out statistical analysis. DMC and DRB participated in the design of the experiments and provided a review of the manuscript. All authors read and approved the final manuscript.

\section{Acknowledgements \\ This work was supported by grants from the Pacific Southwest Regional Center of Excellence for Biodefense \& Emerging Infectious Diseases Research (U54Al065359) and from the National Center for Research Resources (NCRR), a component of the National Institutes of Health $(\mathrm{NIH})$, and the $\mathrm{NIH}$ Roadmap for Medical Research (UL1 RR031985). We thank Alan Barbour MD and the Institute for Clinical Translational Research Center (ICTS) at the University of California, Irvine.}

\section{Author details}

'Department of Chemistry, University of California, Irvine, CA 92697, USA. ${ }^{2}$ Department of Pediatrics, University of California, Irvine, CA 92697, USA. ${ }^{3}$ Institute for Clinical and Translational Sciences, University of California, Irvine, CA 92697, USA.
Received: 4 April 2013 Accepted: 24 June 2013

Published: 10 July 2013

\section{References}

1. Amann A, Spanel P, Smith D: Breath analysis: the approach towards clinical applications. Mini Rev Med Chem 2007, 7(2):115-129.

2. Bajtarevic A, Ager C, Pienz M, Klieber M, Schwarz K, Ligor M, et al: Noninvasive detection of lung cancer by analysis of exhaled breath. BMC Cancer 2009, 9:348.

3. Galassetti PR, Novak B, Nemet D, Rose-Gottron C, Cooper DM, Meinardi S, et al: Breath ethanol and acetone as indicators of serum glucose levels: an initial report. Diabetes Technol Ther 2005, 7(1):115-123.

4. Lee J, Ngo J, Blake D, Meinardi S, Pontello AM, Newcomb R, et al: Improved predictive models for plasma glucose estimation from multi-linear regression analysis of exhaled volatile organic compounds. J Appl Physiol 2009, 107(1):155-160.

5. Ligor M, Ligor T, Bajtarevic A, Ager C, Pienz M, Klieber M, et al: Determination of volatile organic compounds in exhaled breath of patients with lung cancer using solid phase microextraction and gas chromatography mass spectrometry. Clin Chem Lab Med 2009, 47(5):550-560.

6. Novak BJ, Blake DR, Meinardi S, Rowland FS, Pontello A, Cooper DM, et al: Exhaled methyl nitrate as a noninvasive marker of hyperglycemia in type 1 diabetes. Proc Natl Acad Sci U S A 2007, 104(40):15613-15618.

7. Shin HW, Rose-Gottron CM, Cooper DM, Newcomb RL, George SC: Airway diffusing capacity of nitric oxide and steroid therapy in asthma. J Appl Physiol 2004, 96(1):65-75

8. Allardyce RA, Langford VS, Hill AL, Murdoch DR: Detection of volatile metabolites produced by bacterial growth in blood culture media by selected ion flow tube mass spectrometry (SIFT-MS). J Microbiol Methods 2006, 65(2):361-365.

9. Bunge M, Araghipour N, Mikoviny T, Dunkl J, Schnitzhofer R, Hansel A, et al: On-line monitoring of microbial volatile metabolites by proton transfer reaction-mass spectrometry. Appl Environ Microbiol 2008, 74(7):2179-2186.

10. Lechner M, Fille M, Hausdorfer J, Dierich MP, Rieder J: Diagnosis of bacteria in vitro by mass spectrometric fingerprinting: a pilot study. Curr Microbiol 2005, 51(4):267-269.

11. Lechner M, Tilg H, Rieder J: Analysis of volatile compounds emitted by the Helicobacter pylori reference strain NCTC 11637 in vitro. Helicobacter 2006, 11(1):66.

12. Moularat $\mathrm{S}$, Robine $\mathrm{E}$, Ramalho O, Oturan MA: Detection of fungal development in a closed environment through the identification of specific VOC: demonstration of a specific VOC fingerprint for fungal development. Sci Total Environ 2008, 407(1):139-146.

13. Zhu J, Bean HD, Kuo YM, Hill JE: Fast detection of volatile organic compounds from bacterial cultures by secondary electrospray ionization-mass spectrometry. J Clin Microbiol 2010, 48(12):4426-4431.

14. Kamboures MA, Blake DR, Cooper DM, Newcomb RL, Barker M, Larson JK, et al: Breath sulfides and pulmonary function in cystic fibrosis. Proc Natl Acad Sci U S A 2005, 102(44):15762-15767.

15. Lechner M, Karlseder A, Niederseer D, Lirk P, Neher A, Rieder J, et al: H. pylori infection increases levels of exhaled nitrate. Helicobacter 2005 10(5):385-390

16. Shin HW, Umber BJ, Meinardi S, Leu SY, Zaldivar F, Blake DR, et al: Acetaldehyde and hexanaldehyde from cultured white cells. J Trans/ Med 2009, 7:31.

17. Colman JJ, Swanson AL, Meinardi S, Sive BC, Blake DR, Rowland FS: Description of the analysis of a wide range of volatile organic compounds in whole air samples collected during PEM-tropics A and B. Anal Chem 2001, 73(15):3723-3731.

18. Shin HW, Umber BJ, Meinardi S, Leu SY, Zaldivar F, Blake DR, et al: Gas signatures from cultured neutrophils and peripheral blood mononuclear cells obtained from healthy humans. J fo Mol Biomark Diagnosis 2012, 2(4):112.

19. Benjamini $Y$, Hochberg $Y$ : Controlling the false discovery rate: a practical and powerful approach to multiple testing. J Royal Stat Soc B 1995, 57:289-300

20. Cañavate JP, Lubian LM: Relationship between cooling rates, cryoprotectant concentrations and salinities in the cryopreservation of marine microalgae. Mar Biol 1995, 124(2):325-334.

21. Sunda W, Kieber DJ, Kiene RP, Huntsman S: An antioxidant function for DMSP and DMS in marine algae. Nature 2002, 418(6895):317-320. 
22. Dacey JW, Wakeham SG: Oceanic dimethylsulfide: production during zooplankton grazing on phytoplankton. Science 1986, 233(4770):1314-1316.

23. Johnston AW, Todd JD, Sun L, Nikolaidou-Katsaridou MN, Curson AR, Rogers $\mathrm{R}$ : Molecular diversity of bacterial production of the climate-changing gas, dimethyl sulphide, a molecule that impinges on local and global symbioses. J Exp Bot 2008, 59(5):1059-1067.

24. Todd JD, Rogers R, Li YG, Wexler M, Bond PL, Sun L, et al: Structural and regulatory genes required to make the gas dimethyl sulfide in bacteria. Science 2007, 315(5812):666-669.

25. Curson AR, Todd JD, Sullivan MJ, Johnston AW: Catabolism of dimethylsulphoniopropionate: microorganisms, enzymes and genes. Nat Rev Microbiol 2011, 9(12):849-859.

26. Allardyce RA, Hill AL, Murdoch DR: The rapid evaluation of bacterial growth and antibiotic susceptibility in blood cultures by selected ion flow tube mass spectrometry. Diagn Microbiol Infect Dis 2006, 55(4):255-261.

27. Alterthum F, Ingram LO: Efficient ethanol production from glucose, lactose, and xylose by recombinant Escherichia coli. Appl Environ Microbiol 1989, 55(8):1943-1948.

28. Boumba VA, Economou V, Kourkoumelis N, Gousia P, Papadopoulou C Vougiouklakis T: Microbial ethanol production: experimental study and multivariate evaluation. Forensic Sci Int 2011, 215(1-3):189-198.

29. Donnelly MI, Millard CS, Clark DP, Chen MJ, Rathke JW: A novel fermentation pathway in an Escherichia coli mutant producing succinic acid, acetic acid, and ethanol. App/ Biochem Biotechnol 1998, 70-72:187-198.

30. Huerta-Beristain G, Utrilla J, Hernandez-Chavez G, Bolivar F, Gosset G, Martinez A: Specific ethanol production rate in ethanologenic Escherichia coli strain KO11 Is limited by pyruvate decarboxylase. J Mol Microbiol Biotechnol 2008, 15(1):55-64.

31. Martin GJ, Knepper A, Zhou B, Pamment NB: Performance and stability of ethanologenic Escherichia coli strain FBR5 during continuous culture on xylose and glucose. J Ind Microbiol Biotechnol 2006, 33(10):834-844.

32. Padukone N, Evans KW, McMillan JD, Wyman CE: Characterization of recombinant E. coli ATCC 11303 (pLOI 297) in the conversion of cellulose and xylose to ethanol. App/ Microbiol Biotechnol 1995, 43(5):850-855.

33. Salaspuro V, Nyfors $S$, Heine R, Siitonen A, Salaspuro M, Jousimies-Somer $H$ : Ethanol oxidation and acetaldehyde production in vitro by human intestinal strains of Escherichia coli under aerobic, microaerobic, and anaerobic conditions. Scand J Gastroenterol 1999, 34(10):967-973.

34. Sanny T, Arnaldos M, Kunkel SA, Pagilla KR, Stark BC: Engineering of ethanolic E. coli with the Vitreoscilla hemoglobin gene enhances ethanol production from both glucose and xylose. App/ Microbiol Biotechnol 2010, 88(5):1103-1112.

35. Turner C, Spanel P, Smith D: A longitudinal study of ethanol and acetaldehyde in the exhaled breath of healthy volunteers using selected-ion flow-tube mass spectrometry. Rapid Commun Mass Spectrom 2006, 20(1):61-68.

36. Fuchs $\mathrm{P}$, Loeseken $\mathrm{C}$, Schubert JK, Miekisch W: Breath gas aldehydes as biomarkers of lung cancer. Int J Cancer 2010, 126(11):2663-2670.

37. Sponring A, Filipiak W, Mikoviny T, Ager C, Schubert J, Miekisch W, et al: Release of volatile organic compounds from the lung cancer cell line $\mathrm{NCl}-\mathrm{H} 2087$ in vitro. Anticancer Res 2009, 29(1):419-426.

38. Filipiak W, Sponring A, Filipiak A, Ager C, Schubert J, Miekisch W, et al: TDGC-MS analysis of volatile metabolites of human lung cancer and normal cells in vitro. Cancer Epidemiol Biomark Prev 2010, 19(1):182-195.

39. Filipiak W, Sponring A, Mikoviny T, Ager C, Schubert J, Miekisch W, et al: Release of volatile organic compounds (VOCs) from the lung cancer cell line CALU-1 in vitro. Cancer Cell Int 2008, 8:17.

40. Hazen SL, Hsu FF, D'Avignon A, Heinecke JW: Human neutrophils employ myeloperoxidase to convert alpha-amino acids to a battery of reactive aldehydes: a pathway for aldehyde generation at sites of inflammation. Biochemistry 1998, 37(19):6864-6873.

41. Hazen SL, D'Avignon A, Anderson MM, Hsu FF, Heinecke JW: Human neutrophils employ the myeloperoxidase-hydrogen peroxide-chloride system to oxidize alpha-amino acids to a family of reactive aldehydes. Mechanistic studies identifying labile intermediates along the reaction pathway. J Biol Chem 1998, 273(9):4997-5005.

42. Manolis A: The diagnostic potential of breath analysis. Clin Chem 1983, 29(1):5-15.

43. Jain $R$, Yan $Y$ : Dehydratase mediated 1-propanol production in metabolically engineered Escherichia coli. Microb Cell Fact 2011, 10:97.
44. Vujasinovic M, Kocar M, Kramer K, Bunc M, Brvar M: Poisoning with 1propanol and 2-propanol. Hum Exp Toxicol 2007, 26:975-978.

45. Karl T, Prazeller P, Mayr D, Jordan A, Rieder J, Fall R, Lindinger W: Human breath isoprene and its relation to blood cholesterol levels: new measurements and modeling. J App/ Physiol 2001, 91(2):762-770.

46. Smith D, Spanel P, Enderby B, Lenney W, Turner C, Davies SJ: Isoprene levels in the exhaled breath of 200 healthy pupils within the age range 7-18 years studied using SIFT-MS. J Breath Res 2010, 4(1):017101.

47. Davies S, Spanel P, Smith D: A new 'online' method to measure increased exhaled isoprene in end-stage renal failure. Nephrol Dial Transplant 2001, 16(4):836-839.

48. Kuzma J, Nemecek-Marshall M, Pollock WH, Fall R: Bacteria produce the volatile hydrocarbon isoprene. Curr Microbio/ 1995, 30(2):97-103.

doi:10.1186/2001-1326-2-13

Cite this article as: Umber et al.: Gas signatures from Escherichia coli and Escherichia coli-inoculated human whole blood. Clinical and Translational Medicine 2013 2:13.

\section{Submit your manuscript to a SpringerOpen ${ }^{\odot}$ journal and benefit from:}

- Convenient online submission

- Rigorous peer review

- Immediate publication on acceptance

- Open access: articles freely available online

- High visibility within the field

- Retaining the copyright to your article

Submit your next manuscript at $>$ springeropen.com 